\title{
Propensity analysis of survival after subcoronary or root replacement techniques for homograft aortic valve replacement
}

\author{
Ayyaz Ali, MRCS, Yasir Abu-Omar, MRCS, Amit Patel, MBBS, Ahmad Y. Sheikh, MD, Ziad Ali, MRCS, MRCP, PhD, \\ Amber Saeed, MBBS, Asim Akhtar, BS, Thanos Athanasiou, PhD, FETCS, and John Pepper, FRCS
}

\begin{abstract}
Objective: Homograft aortic valve replacement is associated with excellent clinical and hemodynamic outcomes. Valves are implanted predominantly by using 2 techniques: the freehand subcoronary technique or as an aortic root replacement. Our aim was to identify any difference in survival, durability, and clinical performance.
\end{abstract}

\begin{abstract}
Methods: Demographic, operative, and clinical data were obtained retrospectively through case-note review. All operations were performed by a single surgeon. Propensity score-adjusted analysis was used by developing a nonparsimonious logistic regression model for implantation with subcoronary versus root replacement. Actuarial survival and freedom from valve-related events were compared with Kaplan-Meier curves and multivariable proportional hazard Cox regression.
\end{abstract}

Results: Between January 1, 1991, and January 1, 2001, 215 patients underwent aortic valve replacement with a homograft. The subcoronary technique was used in 131 (61\%) patients. Eighty-four (39\%) patients underwent free-standing aortic root replacement. After propensity risk adjustment, the subcoronary implantation technique was associated with a decreased risk of 30-day death (adjusted odds ratio, 0.18; 95\% confidence interval, $0.06-0.34 ; P=.03$ ). Technique of insertion was not an independent predictor of overall mortality during follow-up after adjustment (propensity adjusted hazard ratio, 0.35; 95\% confidence interval, 0.09-1.41; $P=.18$ ). There were no significant differences in 1- and 5-year actuarial survival, freedom from structural valve disease, endocarditis, or reoperation.

Conclusions: Both the subcoronary and root replacement techniques for homograft aortic valve replacement are associated with excellent midterm survival and clinical performance. Root replacement was associated with an increased risk of perioperative death after adjustment for covariates by using propensity analysis.

Since its introduction, the aortic valve homograft has been used successfully for almost 50 years. ${ }^{1-3}$ Two predominant methods are used for homograft valve implantation. The initial experience was with subcoronary implantation within the patient's native aortic root. ${ }^{1}$ More recently, there has been an increased tendency towards using the homograft for total root replacement (RR). ${ }^{4}$ Several comparisons of clinical performance and durability have been undertaken over the past 2 decades. ${ }^{5-14}$ The overwhelming feature of these studies is that significant heterogeneity has often existed between the 2 groups. Our aim was to use propensity scoring to minimize bias, thereby allowing for a more accurate comparison of the 2 implantation techniques in an attempt to ascertain their true effect on clinical outcome after homograft aortic valve replacement (AVR).

From the Department of Cardiothoracic Surgery, Royal Brompton Hospital, London, United Kingdom.

Received for publication Dec 1, 2007; revisions received Sept 5, 2008; accepted for publication Oct 9, 2008.

Address for reprints: Ayyaz Ali, MRCS, Department of Cardiothoracic Surgery, Royal Brompton Hospital, Sydney St, London SW3 3NP, United Kingdom (E-mail:

Ayyaz75@gmail.com).

J Thorac Cardiovasc Surg 2009; 137:334-41

$0022-5223 / \$ 36.00$

Copyright $@ 2009$ by The American Association for Thoracic Surgery doi:10.1016/j.jtcvs.2008.10.015

\section{MATERIALS AND METHODS}

This is a retrospective review of a consecutive series of patients who underwent AVR with a homograft from 1991 to 2001. Patients were not excluded from analysis if they had additional concomitant cardiac procedures.

\section{Homograft Preservation Technique}

An established homograft cryopreservation protocol has been in place at our institution for more than 15 years. After sterile procurement, homografts are placed in nutrient antibiotic solution (Gaya 5) and stored in an incubator at $37^{\circ} \mathrm{C}$ for 24 hours before refrigeration at $4^{\circ} \mathrm{C}$. A cryoprotectant (dimethyl sulfoxide) is added before the valve is placed in a heat-sealed double-sterile barrier comprised of a sterile nylon pouch and a sterile trilaminate aluminium sachet. The sachet is placed in a controlled-rate freezer, which maintains a constant freezing rate of $-1^{\circ} \mathrm{C} / \mathrm{min}$. At $-60^{\circ} \mathrm{C}$, the sachet is transferred to an ultralow freezer and is stored at $-130^{\circ} \mathrm{C}$ for up to 5 years. For the purpose of microbiologic screening, 2 sets of tissue samples are removed from the valve at the time of dissection and subjected to identical treatment and conditions as the homograft. After 24 hours of incubation, the first set of tissue samples is cultured for bacterial and fungal contaminants, and the second set is cultured when the valve is wrapped and packed.

\section{Surgical Technique}

Operations were performed by a single surgeon (J.P.). Although the choice of implant technique was tailored to the individual, homografts were used more frequently for endocarditis, aortic root disease, and aortic valve reoperation. All procedures were performed during cardiopulmonary bypass with cooling to $28^{\circ} \mathrm{C}$, and myocardial protection was undertaken with antegrade and retrograde cold blood cardioplegia. With the 


\section{Abbreviations and Acronyms \\ $\mathrm{AVR}=$ aortic valve replacement \\ $\mathrm{CI}=$ confidence interval \\ $\mathrm{IQR}=$ interquartile range \\ $\mathrm{RR}=$ root replacement}

subcoronary technique, all of the valve sinuses were excised. The valve was then implanted with separate inflow and outflow suture lines, with the latter anchoring the commissures and the scalloped edge of the valve to the aortic wall. For the free-standing RR technique, the allograft was anastomosed en bloc to the aortic annulus proximally and the ascending aorta distally. The coronary ostia were then reimplanted as buttons within the allograft.

\section{Data Acquisition}

Demographic, clinical, and operative data were obtained from individual patient hospital records. Our follow-up protocol included annual echocardiograms to assess cardiac and homograft valve function. Ethical approval for the use of patient data was obtained from our institutional review board. Serial echocardiographic reports were scrutinized for evidence of structural valve deterioration or nonstructural dysfunction. Mortality was determined by using the National Health Service Strategic Tracing System, and survivors were contacted by telephone for interview. Operational definitions were according to joint guidelines of the Society of Thoracic Surgeons and the American Association for Thoracic Surgery. ${ }^{15}$

\section{Echocardiographic Details}

Patients in our series had yearly echocardiographic follow-up at our institution. Transthoracic echocardiography was performed with the Sonos 5000 (Hewlett-Packard, Palo Alto, Calif). Two-dimensional images were obtained by using standard apical, 5-chamber, parasternal short- and longaxis views. Continuous-wave Doppler scanning was used to determine the presence and severity of any regurgitation.

\section{Definition of Study End Point and Follow-up}

The main end points of interest were 30-day mortality and survival at follow-up. Secondary end points were valve-related events at follow-up, such as structural valve degeneration, need for reoperation, and endocarditis. Clinical follow-up data were collected at each clinic visit. Surviving patients remained under this annual follow-up protocol. Survival and freedom from events commenced at the time of operation and ended at the time of death/event or at last follow-up (censoring).

\section{Statistical Methods}

Continuous variables were presented as means \pm standard deviations or medians with interquartile ranges (IQRs) for normally and nonnormally distributed measures, respectively. Categorical variables were shown as percentages. Comparisons for continuous variables were performed with Student's $t$ or Mann-Whitney $U$ tests, and those for binary variables were performed with $\chi^{2}$ or Fischer's exact tests, where appropriate.

For binary outcomes, such as 30-day mortality and identification of predictors, logistic regression was used. Actuarial outcomes were compared with Kaplan-Meier curves and multivariable Cox proportional hazards regression. A log-rank test was used to determine whether significant differences existed between curves. The proportional hazard assumption was tested for each covariate by using 2 methods: (1) correlating the corresponding scaled Schoenfeld residuals with the rank of time and (2) using the procedure "stphtest" in Stata (StataCorp, College Station, Tex). The linearity assumption for each binary covariate was assessed graphically with Martingale residuals. Especially for the propensity score, which was used as the linear term (continuous) in Cox regression, we assessed linearity in the following way: first we categorized the propensity variable into 5 dichotomous variables of equal units, then we inserted each of these in the multivariable analysis to calculate their coefficients, and finally the coefficients were graphed against the midpoint of each propensity score variable. All statistical tests were 2-sided. In all cases corrections were not made for multiple comparisons. Statistical analysis was performed with SPSS 14.0 (SPSS, Inc, Chicago, Ill) and Stata 9.0 (Stata Corp, College Station, Tex) software.

The statistical analysis addressed confounding factors (patient selection) by use of a propensity score and heterogeneity (risk factors) by means of multivariate risk factor analysis. ${ }^{16,17}$

The following models were used in our analysis: (1) unadjusted model, (2) model adjusted for propensity score, and (3) model adjusted for covariates.

Propensity score model. A propensity score for each patient was calculated to determine the probability of allocation to either of the 2 groups and compared (subcoronary $=1 \mathrm{vs} R R=0$ ) by using a nonparsimonious logistic regression model. The discrimination of the propensity model was assessed with calculation of the c-statistic. All the variables listed in Table 1 were included in this model, along with clinically valid interactions. The selection of variables included in the propensity model was based first on clinical grounds (taking into account that the independent variable is a preoperative factor that might be related to surgical technique selection), second on the percentage of missing data for each candidate variable (only variables with completeness of data were included), and finally on the value of the c-statistic to assess the model. The score was subsequently incorporated into the proportional-hazards models as a covariate. We used the propensity score for adjustment and not for matching to avoid reduction in study size. The propensity score analysis was performed as previously recommended. ${ }^{18,19}$

Covariates model. A multivariable regression analysis was performed to elucidate associated causative factors to the outcomes of interest. Initially, univariate regression analysis was used to determine all significant confounding variables (covariates). Those associated confounding variables were subsequently included in the multivariable regression model. Only statistically or clinically significant $(P \leq .1)$ causative factors from the univariate analysis were adjusted for (included) in the multivariable model. Model fit was evaluated by using the Hosmer and Lemeshow goodness-of-fit statistic. All statistical analysis was performed with SPSS 14.0 (SPSS, Inc) software.

\section{RESULTS}

Between January 1, 1991, and January 1, 2001, 215 patients underwent AVR with a homograft. The subcoronary technique was used in $131(61 \%)$ patients, and $84(39 \%)$ patients underwent RR. Patient characteristics according to implant method are demonstrated in Table 2. Subcoronary implantation was used more commonly for degenerative calcific aortic stenosis $(P<.001)$. Alternately, RR was the preferred technique when aortic regurgitation was the predominant valve lesion or in patients with ascending aortic aneurysmal disease $(P<.001)$. The RR technique was also used more frequently for endocarditis $(P=.003)$ and redo aortic valve operations $(P<.001)$, considerably increasing the risk profile of this group. Concomitant coronary artery bypass grafting was more commonly performed in patients who underwent subcoronary allograft implantation.

Thirty-day mortality was significantly greater among patients who underwent RR $(14.2 \%$ vs $2.2 \%, P<.001)$. The causes of 30-day mortality are presented in Table 3 . 
TABLE 1. Baseline characteristics according to implantation technique

\begin{tabular}{|c|c|c|c|}
\hline & Subcoronary & $\begin{array}{c}\text { Root } \\
\text { replacement }\end{array}$ & $\begin{array}{c}P \\
\text { value }\end{array}$ \\
\hline No. & 131 & 84 & \\
\hline \multicolumn{4}{|l|}{ Demographics } \\
\hline Age $>70 y, n(\%)$ & $41(31)$ & $25(30)$ & .81 \\
\hline Male sex, $\mathrm{n}(\%)$ & $93(71)$ & $66(79)$ & .21 \\
\hline \multicolumn{4}{|l|}{ Risk factors } \\
\hline Hypercholesterolemia, n (\%) & $13(10)$ & $9(11)$ & .85 \\
\hline Diabetes, n (\%) & $10(8)$ & $3(4)$ & .26 \\
\hline Hypertension, n (\%) & $31(24)$ & $19(23)$ & .86 \\
\hline Creatinine $>150 \mu \mathrm{mol} / \mathrm{L}, \mathrm{n}(\%)$ & $31(24)$ & $17(20)$ & .56 \\
\hline \multicolumn{4}{|l|}{ Other clinical data } \\
\hline LV impairment, $n(\%)$ & $27(21)$ & $19(23)$ & .72 \\
\hline Pre-NYHA III/IV, n (\%) & $78(60)$ & $50(60)$ & .99 \\
\hline Pre-sinus rhythm, n (\%) & $32(24)$ & $26(31)$ & .29 \\
\hline ACE inhibitor, $\mathrm{n}(\%)$ & $31(24)$ & $30(54)$ & .06 \\
\hline Prosthesis size $>25 \mathrm{~mm}, \mathrm{n}(\%)$ & $6(4.6)$ & $3(4)$ & .719 \\
\hline Concomitant CABG, n (\%) & $34(26)$ & $9(11)$ & .006 \\
\hline \multicolumn{4}{|l|}{ Cause } \\
\hline Degenerative, n (\%) & $96(73)$ & $26(31)$ & $<.001$ \\
\hline Rheumatic, n (\%) & $14(11)$ & $3(4)$ & .07 \\
\hline Endocarditis, n (\%) & $7(5)$ & $15(18)$ & .003 \\
\hline Annular dilatation, n (\%) & $0(0)$ & $21(25)$ & $<.001$ \\
\hline Redo, n (\%) & $14(11)$ & $18(21)$ & .03 \\
\hline Congenital, n (\%) & $0(0)$ & $1(0)$ & .39 \\
\hline \multicolumn{4}{|l|}{ Operative indication } \\
\hline Aortic stenosis, n (\%) & $88(67)$ & $26(31)$ & $<.001$ \\
\hline Aortic regurgitation, $\mathrm{n}(\%)$ & $24(18)$ & $45(54)$ & $<.001$ \\
\hline Mixed valve disease, $\mathrm{n}(\%)$ & $18(13)$ & $13(16)$ & .72 \\
\hline Redo operation, n (\%) & $16(12)$ & $30(36)$ & $<.001$ \\
\hline
\end{tabular}

$L V$, Left ventricular; $N Y H A$, New York Heart Association; $A C E$, angiotensin-converting enzyme; $C A B G$, coronary artery bypass grafting.

After propensity risk adjustment, the subcoronary implantation technique was associated with a decreased risk of 30-day death (adjusted odds ratio, $0.18 ; 95 \%$ confidence interval $[\mathrm{CI}], 0.06-0.34 ; P=.03)$. The median follow-up time was 3.9 years (IQR, 1.6-5.7). There were 25 deaths: 10 in the subcoronary group and 15 in the RR group. There were no deaths beyond 1 year in the RR group. The Kaplan-Meier 1- and 5-year mortality risks were $88.4 \% \pm 4 \%$ and $88.4 \% \pm 4 \%$ for the RR group and $97 \% \pm 1.7 \%$ and $93 \% \pm 3 \%$ for the subcoronary group (Figure 1). KaplanMeier analysis did not reveal a significant difference in survival between the 2 groups (log-rank $\chi^{2}=1.87, P=.176$ ). Subcoronary implantation was not associated with a significantly lower risk of late mortality (unadjusted hazard ratio, $0.47 ; 95 \% \mathrm{CI}, 0.15-1.4 ; P=.18$ ). After propensity risk adjustment, there remained no association between implant technique and an increased risk of late mortality across follow-up (propensity-adjusted hazard ratio, $0.35 ; 95 \% \mathrm{CI}$, $0.09-1.41 ; P=.18$ ). The proportionality and linearity assumptions were not found to be violated. The only
TABLE 2. Causes of 30-day mortality

\begin{tabular}{|c|c|}
\hline & Postoperative day \\
\hline \multicolumn{2}{|l|}{ Subcoronary } \\
\hline Multiorgan failure & 2 \\
\hline CVA & 4 \\
\hline Low cardiac output syndrome & 6 \\
\hline \multicolumn{2}{|l|}{ Root replacement } \\
\hline Unable to wean from $\mathrm{CPB}$ & 0 \\
\hline Low cardiac output syndrome & 0 \\
\hline Systolic cardiac arrest & 0 \\
\hline Low cardiac output syndrome & 0 \\
\hline Low cardiac output syndrome & 1 \\
\hline $\begin{array}{l}\text { Bleeding, Low cardiac output syndrome (left } \\
\text { ventricular assist device) }\end{array}$ & 1 \\
\hline Multiorgan failure & 2 \\
\hline $\begin{array}{l}\text { Cardiac tamponade, low cardiac output } \\
\text { syndrome }\end{array}$ & 6 \\
\hline Multiorgan failure & 16 \\
\hline CVA & 18 \\
\hline Multiorgan failure & 19 \\
\hline Multiorgan failure & 21 \\
\hline \multicolumn{2}{|c|}{$C V A$, Cerebrovascular accident; $C P B$, cardiopulmonary bypass. } \\
\hline \multicolumn{2}{|c|}{$\begin{array}{l}\text { independent predictor of late mortality was a redo operation } \\
\text { (hazard ratio, } 3.6 ; 95 \% \mathrm{CI}, 1.1-12.4 ; P=.04 \text { ). Left ventricu- } \\
\text { lar impairment demonstrated a strong trend toward being an } \\
\text { independent predictor of late mortality (hazard ratio, } 3.8 \text {; } \\
95 \% \mathrm{CI}, 0.96-15.5 ; P=.06 \text { ). }\end{array}$} \\
\hline
\end{tabular}

TABLE 3. Predictors of selection for the root replacement or subcoronary technique: Results of nonparsimonious logistic regression modeling used to develop the propensity score

\begin{tabular}{lrc}
\hline \multicolumn{1}{c}{ Predictor } & OR $(\mathbf{9 5} \% \mathbf{C I})$ & $\boldsymbol{P}$ value \\
\hline Degenerative cause & $5.82(2.1-16.81)$ & .001 \\
Rheumatic cause & $11.21(2.5-50.15)$ & .002 \\
Preoperative sinus rhythm & $0.367(0.14-1.01)$ & .05 \\
Age & $1.2(0.54-2.71)$ & .63 \\
Concomitant CABG & $2.64(0.98-7.09)$ & .05 \\
Hypertension & $0.82(0.33-2.03)$ & .67 \\
Creatinine $>150 \mu$ mol/L & $2.16(0.74-6.29)$ & .15 \\
Male sex & $1.01(0.42-2.37)$ & .99 \\
Diabetes mellitus & $1.41(0.27-7.12)$ & .67 \\
Hypercholesterolemia & $1.38(0.42-4.79)$ & .60 \\
Nonelective operation & $1.49(0.36-6.10)$ & .56 \\
Valve size (continuous variable) & $0.89(0.67-1.16)$ & .37 \\
LV impairment & $1.21(0.36-4.05)$ & .75 \\
Endocarditis & $1.28(0.24-5.9)$ & .75 \\
Redo operation & $0.64(0.25-1.68)$ & .36 \\
Preoperative NYHA III/IV & $0.97(0.44-2.13)$ & .95 \\
Aortic regurgitation & $0.85(0.34-2.53)$ & .70 \\
Mixed aortic valve disease & $0.84(0.41-2.91)$ & .78 \\
Aortic stenosis & $1.58(0.20-8.30)$ & .92 \\
Year of operation (first 5 y) & $0.42(0.15-1.15)$ & .24 \\
\hline OR, Odd
\end{tabular}

$O R$, Odds ratio; $C I$, confidence interval; $C A B G$, coronary artery bypass grafting; $L V$, left ventricular; NYHA, New York Heart Association. 


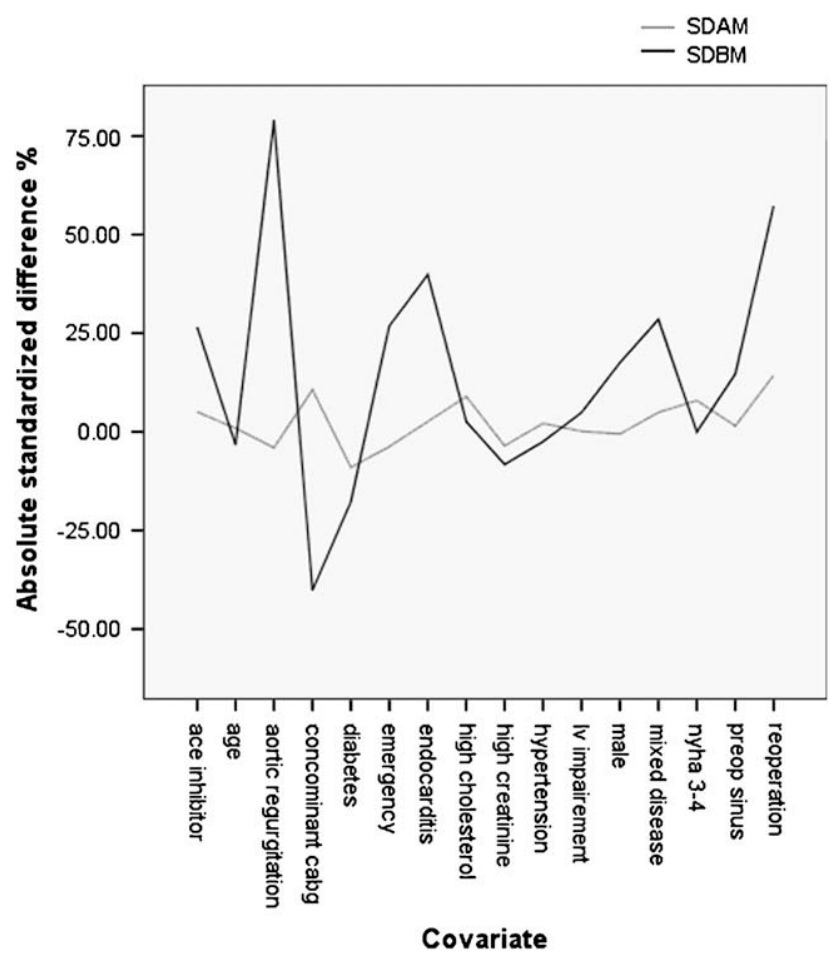

FIGURE 1. Actuarial survival. SCT, Subcoronary implantation; ROOT, root replacement.

\section{Propensity Analysis Model and Adjustment for Covariates Model}

In the subcoronary group patients the median propensity score $(0=\mathrm{RR}$ and $1=$ subcoronary) was 0.71 (IQR, 0.42 ); in patients in the RR group the median score was 0.37 (IQR, 0.48). The c-statistic was 0.81 (area under the curve), indicating satisfactory discrimination. Variables and clinically important interactions included in the propensity score model are listed in Table 3 . We compared the balance of all baseline covariates in Table 1 between treatment groups before and after propensity score matching by using the absolute standardized difference (Figure 2), which directly quantifies the bias in the means (or proportions) of covariates across the groups, although in terms of modeling, as we mentioned earlier, we used the propensity score in the Cox regression model only as a covariate for adjustment because of sample size considerations. Variables included in the propensity score model are listed in Table 3 . The mortality across 5 cohort quintiles of propensity is shown in Table 4. The independent predictors of 30-day mortality and late mortality are presented in Tables 5 and 6 , respectively.

\section{Valve-related Events}

Actuarial freedom from valve-related events was determined by using the Kaplan-Meier product-limit method. Freedom from structural valve deterioration at 1 and 5 years was $98 \% \pm 2 \%$ and $93 \% \pm 5 \%$ for the RR group and

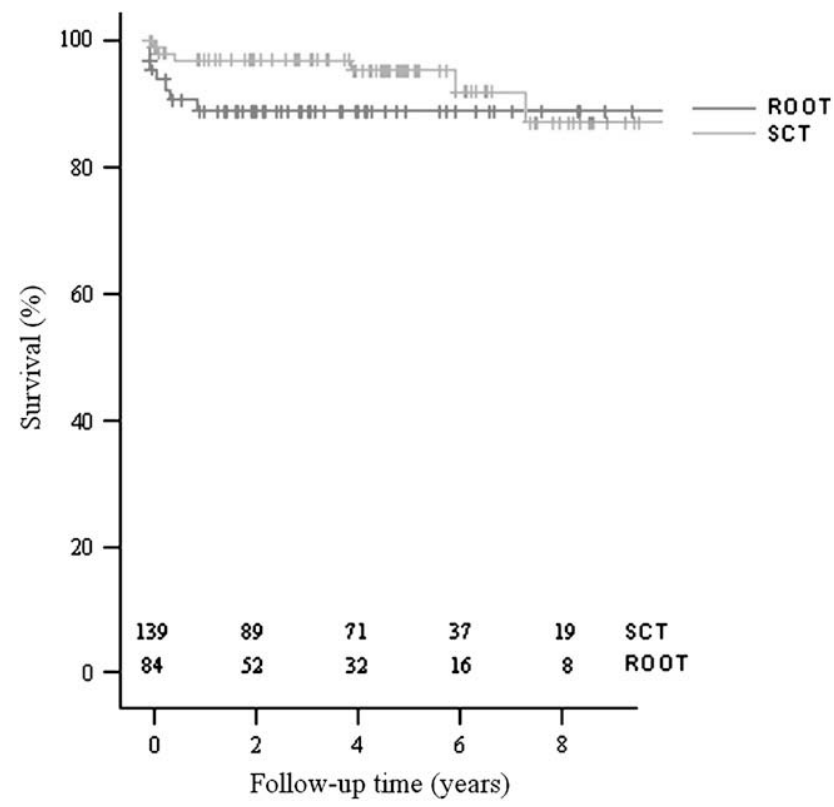

FIGURE 2. Balance in covariates before and after propensity matching. $S D A M$, Standardized difference after matching; SDBM, standardized difference before matching.

$100 \%$ and $93 \% \pm 3 \%$ for the subcoronary group, respectively $(P=.35$, Figure 3$)$. Freedom from endocarditis for the RR group at 1 and 5 years was $100 \%$ and $100 \%$ compared with $97 \% \pm 1.7 \%$ and $97 \% \pm 1.7 \%$ for the subcoronary group, respectively $(P=.18$, Figure 4$)$. Actuarial freedom from reoperation for the RR group was $98 \%$ $\pm 2 \%$ and $95 \% \pm 3.2 \%$ at 1 and 5 years, respectively. For patients in the subcoronary group, the 1 - and 5-year freedom from reoperation was $100 \%$ and $88 \% \pm 5 \%$, respectively (Figure 5). This was not a significant difference when the curves were compared by using the log-rank test $(P=.66)$. Nine patients required reoperation: 6 in the subcoronary group and 3 in the RR group. In 8 patients the predominant valve lesion was aortic regurgitation

TABLE 4. Mortality for patients undergoing the root replacement and subcoronary techniques in quintiles of propensity

\begin{tabular}{llll}
\hline \multirow{2}{*}{$\begin{array}{c}\text { Percentiles of } \\
\text { propensity score }\end{array}$} & \multicolumn{2}{c}{ Technique } \\
\cline { 3 - 4 } First quintile & RR & \multicolumn{1}{c}{ SC } \\
& Patients in quintile & 35 & 5 \\
Second quintile & Deaths (n [\%] of total) & $7(8.3)$ & $0(0)$ \\
& Patients in quintile & 21 & 19 \\
& Deaths (n [\%] of total) & $4(4.8)$ & $4(3.1)$ \\
Third quintile & Patients in quintile & 16 & 34 \\
& Deaths (n [\%] of total) & $1(1.2)$ & $2(1.5)$ \\
Fourth quintile & Patients in quintile & 7 & 35 \\
& Deaths (n [\%] of total) & $1(2.5)$ & $3(2.3)$ \\
Fifth quintile & Patients in quintile & 5 & 37 \\
& Deaths (n [\%] of total) & $2(2.4)$ & $1(1.05)$ \\
\hline
\end{tabular}

$R R$, Root replacement; $S C$, subcoronary technique. 
TABLE 5. Logistic regression analysis (adjusted for covariates model): Independent predictors of 30-day mortality

\begin{tabular}{lcc}
\hline \multicolumn{1}{c}{ Predictor } & OR $(\mathbf{9 5} \% \mathbf{C I})$ & $\boldsymbol{P}$ value \\
\hline Reoperation & $7.9(1.8-34.8)$ & .006 \\
Subcoronary technique & $0.15(0.03-0.88)$ & .04 \\
Degenerative cause & $4.9(0.73-34.0)$ & .10 \\
Endocarditis & $3.2(0.62-16.7)$ & .17 \\
Left ventricular impairment & $2.1(0.44-9.7)$ & .36 \\
Aortic stenosis & $0.40(0.05-3.1)$ & .38 \\
Preoperative sinus rhythm & $2.1(0.44-9.7)$ & .42 \\
Aortic regurgitation & $1.16(0.18-7.2)$ & .87 \\
\hline
\end{tabular}

$O R$, Odds ratio; $C I$, confidence interval.

associated with either commissural leaflet tear or, in 2 patients, leaflet prolapse. Excessive calcification of the previous homograft at explantation was noted in only 1 patient who underwent subcoronary implantation. One patient, who underwent $R R$ as an emergency procedure for endocarditis, required reoperation on the day of the operation to repair the homograft after excessive postoperative bleeding from the aortic suture line. This patient died 18 days later from multiorgan failure.

\section{DISCUSSION}

The aortic homograft has established itself as a reliable valve substitute. Its hemodynamic characteristics are excellent whether implanted in the subcoronary position or used for total RR. ${ }^{20,21}$ The homograft's resistance to infection is a major reason why many surgeons choose to use the prosthesis for AVR in the setting of active endocarditis. ${ }^{5}$ The avoidance of formal anticoagulation and a low incidence of thromboembolism are additional advantages of its use. ${ }^{5}$ These benefits must be balanced against the prospect of eventual valve failure caused by structural degeneration and logistic issues associated with availability, preservation, and storage. Excluding the use of the homograft as an inclusion cylinder, subcoronary implantation and free-standing $\mathrm{RR}$ are the 2 available techniques for valve insertion. Several studies have compared these 2 implant methods with respect to survival, freedom from structural valve disease, and reoperation. ${ }^{5-14}$ The overwhelming obstacle in comparing these

TABLE 6. Cox regression analysis (adjusted for covariates model): Independent predictors of late mortality

\begin{tabular}{lcc}
\hline \multicolumn{1}{c}{ Predictor } & HR $(\mathbf{9 5} \% \mathbf{C I})$ & P value \\
\hline Reoperation & $3.6(1.1-12.4)$ & .04 \\
Left ventricular impairment & $3.9(0.96-15.5)$ & .06 \\
Preoperative sinus rhythm & $1.7(0.44-6.6)$ & .44 \\
Endocarditis & $1.4(0.14-14.4)$ & .75 \\
Aortic stenosis & $0.77(0.14-4.1)$ & .76 \\
Aortic regurgitation & $0.75(0.12-4.6)$ & .75 \\
Subcoronary technique & $1.0(0.24-4.3)$ & .97 \\
\hline
\end{tabular}

$H R$, Hazard ratio; $C I$, confidence interval.

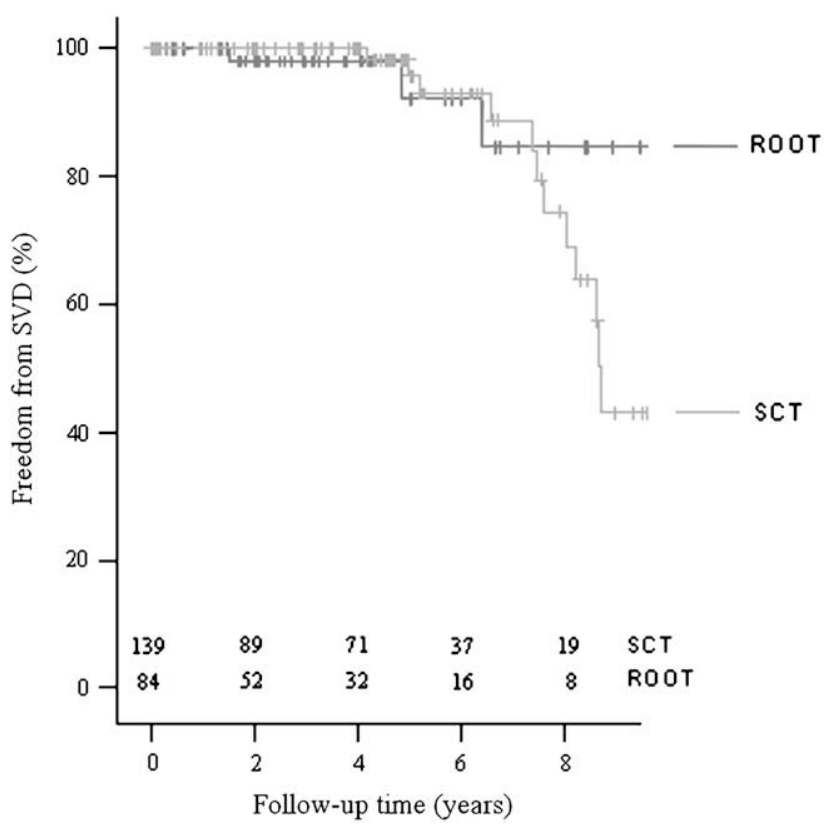

FIGURE 3. Freedom from structural valve deterioration ( $S V D)$ ). $S C T$, Subcoronary implantation; ROOT, root replacement.

2 methods has been that the use of an individual technique is often biased by other operation-related factors. In our series RR was associated with a high early mortality of $14 \%$ compared with $2.2 \%$ for the subcoronary technique. This figure is more easily understood when it is taken into account that $36 \%$ of patients who underwent RR were undergoing a redo AVR, with a further $18 \%$ being treated for active

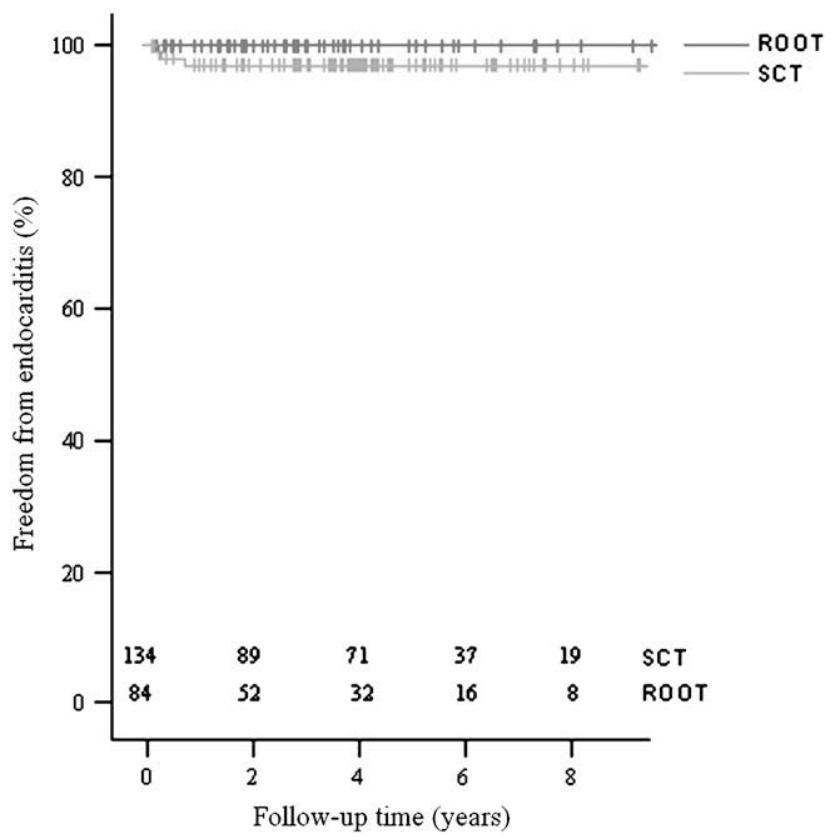

FIGURE 4. Freedom from endocarditis. SCT, Subcoronary implantation; ROOT, root replacement. 


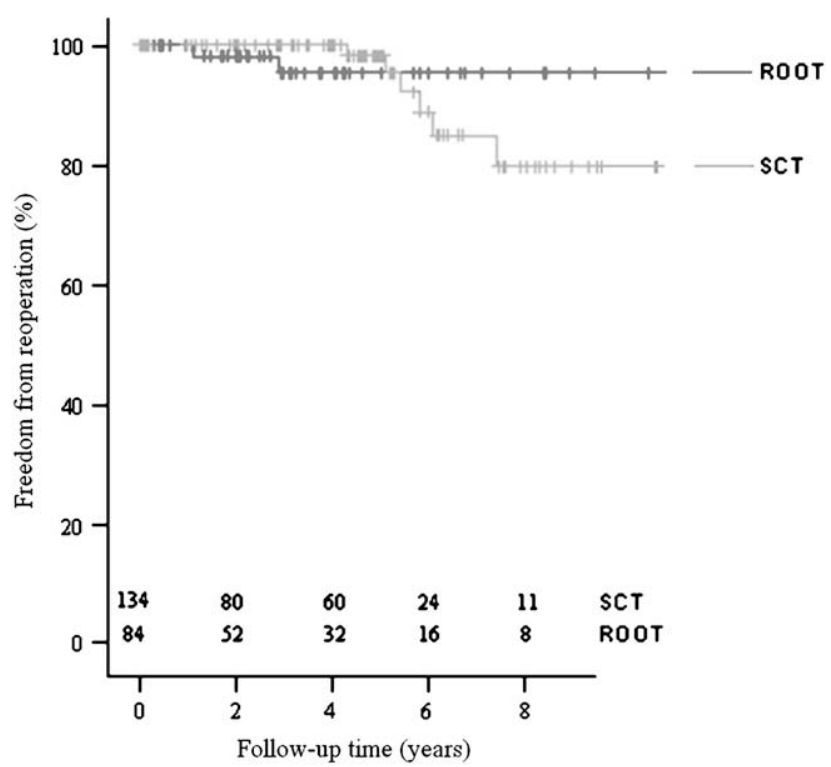

FIGURE 5. Freedom from reoperation. SCT, Subcoronary implantation; $R O O T$, root replacement.

endocarditis. The mortality for elective primary AVR with the RR technique was only $4.4 \%$ (2/45). This finding lends further perspective toward understanding the dramatically different patient risk profiles associated with the 2 techniques of homograft insertion. We used propensity analysis to adjust for such factors and correct for bias associated with allocation to a particular implantation method. The propensity score has been proposed as a better alternative in studies with rare events and multiple baseline characteristics (confounders). ${ }^{22}$ A study by Cepeda and colleagues ${ }^{23}$ compared both techniques. Propensity score analysis performed better than logistic regression analysis in controlling for confounders when there were 7 or fewer events per baseline characteristic.

Use of the RR technique was an independent predictor of 30-day mortality but not for overall mortality. In fact, all deaths in the RR group occurred within the first postoperative year. Beyond this time point, there were no further deaths among patients in this group over the duration of follow-up. It follows that the greatest risk to patients undergoing homograft $\mathrm{RR}$ is in the perioperative and early postoperative periods. Inevitably, total RR is a more radical surgical procedure than subcoronary implantation of an allograft. Reimplantation of the coronary ostia, if complicated by technical error, can lead to myocardial ischemia and perioperative myocardial infarction. Furthermore, there might be an increased tendency for postoperative bleeding because of several external suture lines. These factors can certainly account for some increase in perioperative risk over that seen with subcoronary valve insertion. Three of the early deaths in patients undergoing RR were associated with perioperative bleeding, resulting in postoperative hemorrhage or cardiac tamponade with accompanying hemodynamic compromise. Previous studies have demonstrated an overall survival advantage for the RR technique over subcoronary implantation. ${ }^{5}$ We were unable to demonstrate a survival benefit for RR over subcoronary implantation in our series. Older studies with long follow-up periods frequently span 2 or 3 decades. ${ }^{5,6}$ Over such a protracted length of time, significant changes are bound to occur with respect to all aspects of cardiac surgery, ranging from anesthesia, myocardial protection, and postoperative management to surgical technique, perioperative evaluation of procedure quality, and increasing understanding of disease pathophysiology. In the context of homograft AVR, important changes that have occurred over the past 30 years have included a shift from initial techniques of preservation of allografts by using antibiotic solution to the use of fresh viable allografts and the now preferred and more practical method of cryopreservation. Similarly, there has been a trend over time toward replacing subcoronary implantation with RR. When series of procedures are compared over such widely separated time periods, it is inevitable that changing practice over different eras can prejudice the outcome of any comparison. Although logistic regression and statistical modeling can adjust for many factors, it cannot completely account for all variables related to different time periods. Our study was conducted over a decade, and during this period, protocols for preservation, surgical intervention, and anesthesia remained relatively unchanged.

A number of authors have reported an increased risk of reoperation associated with the subcoronary technique. ${ }^{5,24}$ This has been validated by a recent meta-analysis of several studies comparing the subcoronary and RR techniques for homograft insertion, which also identified an increased risk of reoperation after subcoronary implantation. ${ }^{25}$ There are several reasons for reoperation in patients having undergone homograft AVR. Because the incidence of endocarditis is exceedingly low, as demonstrated in our series and other reports, this is a rare cause for reoperation. The most common cause is structural valve deterioration. Homografts, like all bioprostheses, degenerate over time. Important factors associated with accelerated degeneration have been identified as younger recipient age and older age of the homograft donor. ${ }^{5}$ In our study there was no difference in 1or 5-year actuarial freedom from structural valve disease or reoperation between patients in the subcoronary and RR groups. The major clinical manifestations of structural valve disease are the development of significant aortic insufficiency or aortic stenosis noted by an increasing transvalvular gradient measured by means of echocardiographic analysis. These features can be detected as part of routine investigation or present as a deterioration in the patient's clinical condition. In our series 9 patients required reoperation over the course of follow-up. Six patients previously had a subcoronary allograft, and the remaining 3 underwent RR. In 8 of 
these patients, the valve lesion was aortic insufficiency. This was secondary to leaflet tearing and prolapse, which is indicative of fatigue failure of the valve associated with repetitive strain and insult. Early reoperation is reported to be much more frequent after subcoronary insertion. ${ }^{24}$ Technical errors relating to homograft sizing and failure to achieve appropriate geometry of the allograft within the aortic root are 2 major reasons for early valve failure. Willems and associates $^{24}$ documented that the learning curve associated with subcoronary implantation is a major reason for early reoperation. Such a learning curve inevitably includes the factors mentioned above, which relate to technical details of subcoronary allograft insertion. The number of patients who required reoperation in ours series was low. The absolute incidence was only $4.1 \%(9 / 215)$ over the follow-up period. Five-year actuarial freedom from reoperation was $95 \%$ for RR and $88 \%$ for subcoronary implantation.

Both the subcoronary and RR techniques allow for comparable midterm survival and freedom from structural valve disease and reoperation. The technique used should in all cases be tailored to the individual patient. In our series subcoronary insertion was predominantly used for uncomplicated, degenerative, calcific aortic valve disease. RR is likely to remain the preferred method in the presence of aortic root disease, endocarditis, and aortic valve reoperations. Furthermore, as a consequence of being a more radical procedure, RR might pose greater perioperative risk to the patient, independent of other operation-related factors. After propensity adjustment, RR was an independent predictor of 30-day mortality. Many of these early deaths were caused by low cardiac output syndrome in the early perioperative period. It is conceivable that specific technical details related to RR might be responsible for this observation. The need for reimplantation of the coronary ostia during RR might compromise myocardial perfusion if technical errors were to occur during this component of the procedure. The association between RR and low cardiac output syndrome requires further investigation. Despite a well-recognized risk of valve failure over the longer term, allograft AVR is associated with specific advantages over other prostheses related to their more physiologic performance and low incidence of valve-related morbidity. Furthermore, with improvement in surgical technique, myocardial management, and perioperative patient care, aortic valve reoperation is becoming increasingly safe. ${ }^{26,27}$ Consequently, patients can enjoy the lifestyle benefits that accompany the use of allografts and bioprosthetic AVR in general, secure in the knowledge that the risk associated with redo AVR can be considered far from prohibitive. There remains concern that reoperative procedures in patients with a previous homograft can be a difficult undertaking, particularly when dense calcification of the homograft aortic wall complicates RR. In a previous report we have demonstrated that the use of a homograft at primary operation does not increase the risk of redo AVR. ${ }^{28}$

\section{Study Limitations}

Our study has several limitations, primarily relating to our methodology and sample size. First, it is nearly impossible to account for all the differences between patients and the selection process involved in determining the method of homograft implantation. A principal difficulty is ascertaining whether patients in both groups were suitable for both procedures. This can only be guaranteed in the setting of a randomized controlled trial. Although propensity analyses are a powerful statistical technique, they are inherently limited by the number and accuracy of the variables evaluated. Furthermore, the low perioperative mortality at our institution poses an important limitation with regard to applicability of the data. Finally, because our median follow-up was less than 10 years, the very long-term life expectancy implications for patients in our series remain undetermined. A number of existing studies include longer follow-up periods; however, they did not use propensity analysis to treat allocation bias. ${ }^{16-19}$ The propensity technique used in this study was responsible for the residual imbalance in covariates after propensity score matching, and this needs to be considered as a limitation of our study. It was not possible to apply other techniques to compensate for this because of sample size constraints. Finally, our current length of follow-up does not allow us to comment on differences in clinical outcomes 10 years after AVR by using either technique. We aim to analyze such outcomes in future reports as we gain further follow-up data from our patient cohort.

\section{CONCLUSIONS}

Implantation technique was not associated with any important differences in clinical performance over the longer term in our study. RR was, however, associated with an increase in 30-day mortality. Both methods result in excellent outcomes; however, there remains an attendant risk of structural valve failure that might necessitate reoperation. For almost 5 decades, the aortic homograft has established itself as a reliable valve substitute. The allograft proves itself to be especially valuable in the difficult setting of active endocarditis and redo aortic valve procedures. Both the subcoronary and RR implantation techniques for AVR can be used by the surgeon in the knowledge that they are associated with excellent clinical results. The apparent association between $\mathrm{RR}$ and increased perioperative mortality warrants further investigation.

\section{References}

1. Ross DN. Homograft replacement of the aortic valve. Lancet. 1962;8:487.

2. Kerwin AJ, Lenkei SC, Wilson DR. Aortic-valve homograft in the treatment of aortic insufficiency. Report of nine cases, with one followed for six years. N Engl J Med. 1962;266:852-7.

3. Barratt-Boyes BG. Homograft aortic valve replacement in aortic incompetence and stenosis. Thorax. 1964;19:131-50.

4. Somerville J, Ross D. Homograft replacement of aortic root with reimplantation of coronary arteries. Results after one to five years. Br Heart J. 1982;47:473-82. 
5. Lund O, Chandrasekaran V, Grocott-Mason R, Elwidaa H, Mazhar R, Khagani A, et al. Primary aortic valve replacement with allografts over twenty-five years: valve-related and procedure-related determinants of outcome. J Thorac Cardiovasc Surg. 1999;117:77-90.

6. O'Brien MF, Harrocks S, Stafford EG, Gardner MA, Pohlner PG, Tesar PJ, et al. The homograft aortic valve: a 29 -year, $99.3 \%$ follow-up of 1,022 valve replacements. J Heart Valve Dis. 2001;10:334-45.

7. Kirklin JK, Smith D, Novick W, Naftel DC, Kirklin JW, Pacifico AD, et al. Longterm function of cryopreserved aortic homografts, a ten-year study. J Thorac Cardiovasc Surg. 1993;106:154-66.

8. Shapira OM, Shemin RJ. Aortic valve replacement with cryopreserved allografts: mid-term results. J Card Surg. 1994;9:292-7.

9. Jones EL, Shah VB, Shanewise JS, Martin TD, Martin RP, Coto JA, et al. Should the freehand allograft be abandoned as a reliable alternative for aortic valve replacement? Ann Thorac Surg. 1995;59:1397-404.

10. Yankah AC, Weng Y, Hofmeister J, Alexi-Meskishvilli V, Siniawski H, Lange PE, et al. Freehand subcoronary aortic valve and aortic root replacement with cryopreserved homografts: Intermediate term results. J Heart Valve Dis. 1996;5:498-504.

11. Prager RL, Fischer CR, Kong B, Byrne JP, Jones DJ, Hance ML, et al. The aortic homograft, evolution of indications, techniques, and results in 107 patients. Ann Thorac Surg. 1997;64:659-64.

12. Doty JR, Salazar JD, Liddicoat JR, Flores JH, Doty DB. Aortic valve replacement with cryopreserved aortic allograft: ten-year experience. J Thorac Cardiovasc Surg. 1998;115:371-80.

13. Takkenberg JJ, Van Herwerden LA, Eijkemans MJ, Bekkers JA, Bogers AJ. Evolution of allograft aortic valve replacement over 13 years: results of 275 procedures. Eur J Cardiothorac Surg. 2002;21:683-91.

14. Killian E, Oberhoffer M, Gulbins H, Uhlig A, Kreuzer E, Reichart B. Ten years experience in aortic valve replacement with homografts in 389 cases. J Heart Valve Dis. 2004;13:554-9.

15. Edmunds LH Jr, Clark RE, Cohn LH, Grunkemeier GL, Miller DC, Weisel RD. Guidelines for reporting morbidity and mortality after cardiac valvular operations. Ad Hoc Liaison Committee for Standardizing Definitions of Prosthetic Heart
Valve Morbidity of The American Association for Thoracic Surgery and The Society of Thoracic Surgeons. J Thorac Cardiovasc Surg. 1996;112:708-11.

16. Rosenbaum PR. Discussing hidden bias in observational studies. Ann Intern Med. 1991;115:901-5.

17. Braitman LE, Rosenbaum PR. Rare outcomes, common treatments: analytic strategies using propensity scores. Ann Intern Med. 2002;137:693-5.

18. Rubin DB. Estimating causal effects from large data sets using propensity scores. Ann Intern Med. 1997;127(suppl):757-63.

19. Grunkemeier GL, Payne N, Jin R, Handy JR Jr. Propensity score analysis of stroke after off-pump coronary artery bypass grafting. Ann Thorac Surg. 2002;74:301-5.

20. Kennedy JW, Twiss RD, Blackmon JR, Merendino KA. Hemodynamic studies one year after homograft aortic valve replacement. Circulation. 1968;37(suppl): II110-8.

21. Eriksson MJ, Kallner G, Rosfors S, Ivert T, Brodlin LA. Hemodynamic performance of cryopreserved aortic homograft valves during mid-term follow-up. J Am Coll Cardiol. 1998;32:1002-8.

22. Braitman LE, Rosenbaum PR. Rare outcomes, common treatments, analytic strategies using propensity scores. Ann Intern Med. 2002;13:693-5.

23. Cepeda MS, Boston R, Farrar JT, Strom BL. Comparison of logistic regression versus propensity score when the number of events is low and there are multiple confounders. Am J Epidemiol. 2003;158:280-7.

24. Willems PT, van Herwerden LA, Steyerberg EW, Taams MA, Kleyburg VE, Hokken RB, et al. Subcoronary implantation or aortic root replacement for human tissue valves: sufficient data to prefer either technique? Ann Thorac Surg. 1995; 60:583-6.

25. Athanasiou T, Jones C, Jin R, Grunkemeier GL, Ross DN. Homograft implantation techniques in the aortic position: to preserve or replace the aortic root. Ann Thorac Surg. 2006;81:1578-86.

26. Davierwala PM, Borger MA, David TE, Rao V, Maganti M, Yau TM. Reoperation is not an independent predictor of mortality during aortic valve surgery. J Thorac Cardiovasc Surg. 2006;131:329-35.

27. Kumar P, Athanasiou T, Ali A, Nair S, Oz BS, DeSouza A, et al. Re-do aortic valve replacement: does a previous homograft influence the operative outcome? J Heart Valve Dis. 2004;13:904-12. 